\title{
Analisis SWOT sebagai Perencanaan Strategi Pengembangan Usaha pada Aspek Operasional Perusahaan Cargo PT. Power Express Indonesia
}

\author{
*Mila Priwanti Ningrum, Pribadiyono, Enny Istanti \\ Program Studi Manajemen Fakultas Ekonomi dan Bisnis \\ Universitas Bhayangkara Surabaya, Indonesia
}

\begin{abstract}
Abstrak
DOI: $10.46821 /$ benchmark.v1i2.145

PT. Power Express Indonesia merupakan sebuah perusahaan yang bergerak di bidang jasa pengiriman barang melalui udara (cargo). Tujuan dari penelitian ini adalah melakukan analisis SWOT terhadap PT. Power Express Indonesia untuk mengetahui posisi perusahaan. Melalui analisis SWOT perusahaan mampu melihat kondisi bisnisnya secara keseluruan. PT. Power Express Indonesia berada di kuadran I, posisi ini menandakan perusahaan di posisi kuat dan berpeluang maka strategi yang harus diterapkan adalah SO: Adanya pelatihan bagi karyawan untuk meningkatkan tenaga kerja yang berkualitas memenuhi standart untuk menjaga hubungan baik dengan pelanggan, Keramahan Customer Service dalam bekerja sesuai dengan standart pelayanan yang membuat pelanggan tetap banyak. Dan untuk menghadapi pesaing strategi yang di gunakan perusahaan Matrik Internal-Eksternal yaitu : Meningkatkan kualitas tenaga kerja untuk menghadapi pesaing baru, Meningkatkan pelayanan yang terbaik, Menanggapi komplain pelanggan dengan baik, Meningkatkan jenis usaha yang dikelola sesuai dengan keinginan konsumen, Memberikan harga yang terjangkau dengan kualitas pengiriman yang terbaik.
\end{abstract}

Kata kunci: Analisis SWOT, Strategi Pengembangan, Positioning PT. Power Express Indonesia

\begin{abstract}
PT. Power Express Indonesia is a company engaged in the field of cargo shipping services. The purpose of this study is to conduct a SWOT analysis of PT. Power Express Indonesia to find out the company's position. Through SWOT analysis the company is able to see the business conditions as a whole. PT. Power Express Indonesia is in quadrant I, this position indicates the company is in a strong position and has an opportunity then the strategy that must be applied is SO: There is training for employees to improve quality workforce that meets the standards to maintain good relations with customers, Friendliness of Customer Service in working in accordance with service standards that make many customers remain. And to deal with competitors the strategies used by the company Internal-External Matrix are: Improving the quality of the workforce to deal with new competitors, Improving the best service, Responding to customer complaints properly, Increasing the type of business managed in accordance with consumer desires, Providing affordable prices with the best shipping quality.
\end{abstract}

Keywords: SWOT Analysis, Development Strategy, Positioning of PT. Power ExpressIndonesia.

\section{PENDAHULUAN}

Di Indonesia saat ini, keberadaan cargo mengalami perkembangan yang sangat pesat, terlebih karena kebutuhan manusia juga semakin bertambah. Hal itu pula yang 
menyebabkan masyarakat di Indonesia menginginkan kemudahan dalam berbagai hal terutama untuk hal pengiriman barang. Selain itu, adanya jasa pengiriman cargo dapat menjadi indikator perkembangan ekonomi, khususnya di Indonesia. Adanya sistem jualbeli yang mengandalkan jasa pengiriman barang atau pun cargo menunjukan perkembangan ekonomi negara ini setidaknya bertambah baik.Perusahaan cargo atau jasa pengiriman barang telah menjamur di berbagai tempat dan wilayah. Jasa yang ditawarkan pun juga berbeda-beda sehingga menciptakan kualitas perusahaan yang berbeda pula. Salah satu perusahaan jasa yang sedang berkembang yaitu perusahaan jasa cargo atau pengiriman barangPT. Power Express Indonesia. PT. Power Express Indonesia merupakan sebuah perusahaan yang berdiri di Jawa Timur pada tahun 2010. Latar belakang berdirinya perusahaan ini adalah ingin turut mendukung pekembangan serta pertumbuhan perekonomian di Indonesia khususnya dalam mendistribusikan barang-barang kebutuhan masyarakat serta kebutuhan Industri secara cepat, aman dan effisien. Dengan motto perusahaan "Memang Cepat". Perusahaan jasa cargo ini menawarkan jasa ekspedisi antar barang dengan sistem port-to-portmelalui airlines.

\section{TINJAUAN PUSTAKA}

\section{Manajemen Strategi}

Menurut Sedarmayanti (2017:31), manajemen strategi merupakan proses berkenaan penentuan arah masa depan organisasi dan pelaksanaan keputusan dalam mencapai sasaran jangka pendek dan jangka panjang organisasi/perusahaan.

\section{Sumber Daya Manusia}

Menurut Sodikin (2017:3), manajemen sumber daya manusia merupakan kegiatan perencanaan, pengorganisasian, pengarahan, dan pengawasan individu atau kelompok tenaga kerja agar peranannya lebih efektif dan efesien dalam membantu terwujudnya tujuan tenaga kerja, perusahaan, dan masyarakat.

\section{Matris SWOT}

Menurut Rangkuti (2018:19) analisis SWOT adalah identifikasi berbagai faktor secara sistematis untuk merumuskan strategi perusahaan. Analisis SWOT membandingkan antara faktor eksternal peluang (Opportunities) dan ancaman (Threats) dengan faktor internal kekuatan (Strengths), dan kelemahan (Weaknesses).

\section{Kerangka Konseptual}

Penelitian ini mengenai kondisi PT. Power Express Indonesia dan Strategi perusahaan dalam bidang jasa cargo, sumber daya manusia dan kinerjanya, langka yang dilakukan diawalin dengan menganalisis Faktor internal dan eksternal pada PT. Power Express Indonesia, dan melalui Analisis SWOT dan membandingkan menurut teori kajian pustaka. 


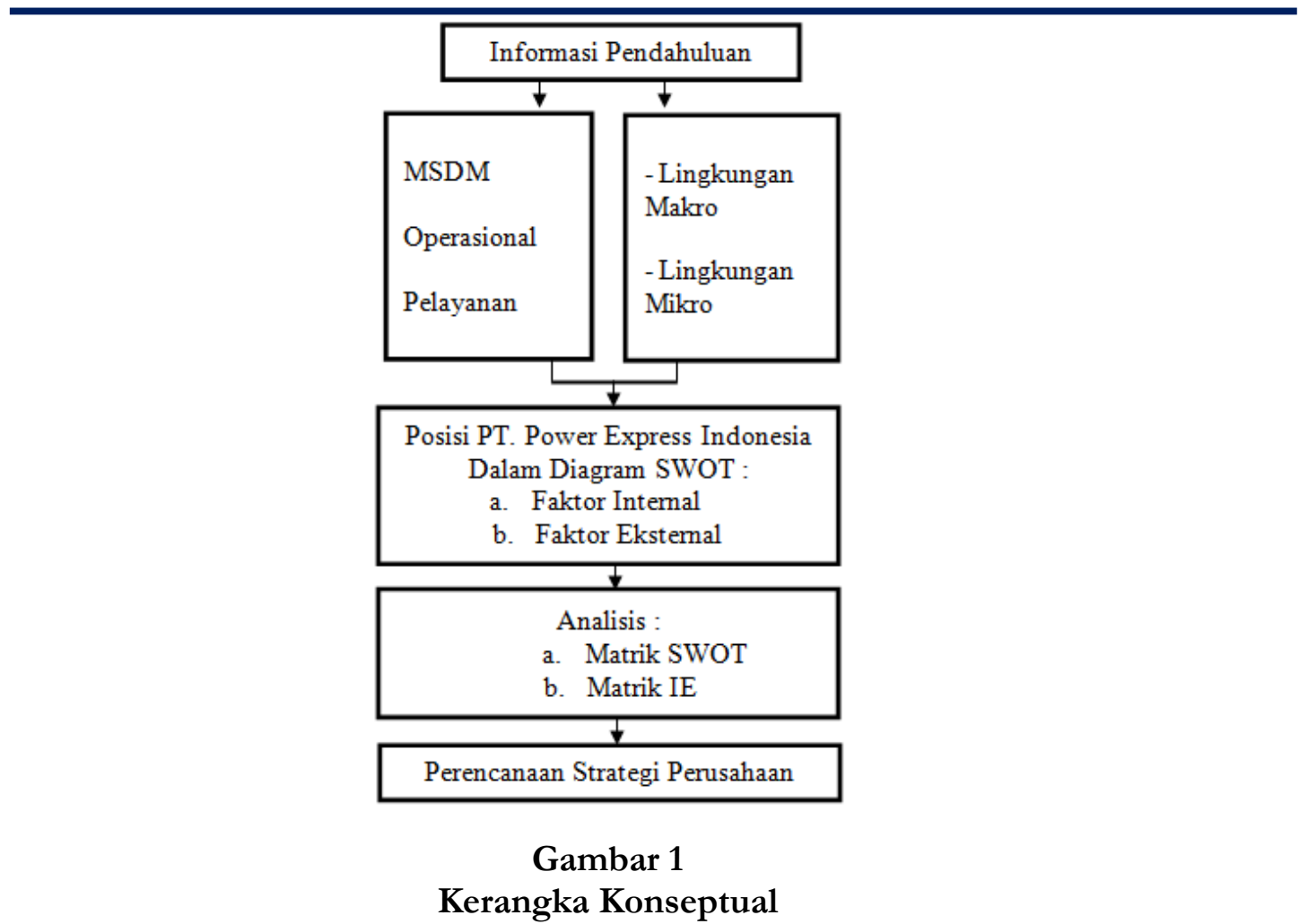

\section{METODE PENELITIAN}

Menurut Rukajat (2018:4) Penelitian kualitatif adalah jenis penelitian yang temuantemuannya tidak diperoleh melalui prosedur kuantifikasi, perhitungan statistik, atau bentuk cara-cara lainnya yang menggunakan ukuran angka.Data yang dikumpulkan berupa kata-kata atau kalimat dari gambaran yang ada bukan berupa nomor atau angka-angka. Penelitian kualitatif menekankan proses bukan hanya tertumpu pada hasil atau produk.

\section{Jenis Data}

Teknik pengumpulan data menjelaskan tentang bagaimana data dikumpulkan sebelum diola. Berdasarkan sumbernya, jenis data di bagi menjadi dua.

Data primer adalah data yang diperoleh PT. Power Express Indonesia baik dengan cara observasi maupun kegiatan wawancara dan hasil kuisioner yang dilakukan dan yang di responden. Data Sekunder adalah data berupa catatan dokumen laporan maupun arsip resmi tersedia di PT. Power Express Indonesia.

\section{Sumber Data}

a. Hasil wawancara dan interview kepada pimpinan dan berbagai karyawan PT. Power Express Indonesia.

b. Dokumen-dokumen yang terdapat diperusahaan, seperti sejarah perusahaan, visi dan misi perusahaan, serta struktur organisasi perusahaan.

c. Buku-buku referensi pendukung untuk melengkapi penelitian mengenai Analisis SWOT untuk merencanakan strategi perusahaan.

d. Jurnal Skripsi terdahulu yang dapat menjadi bahan studi pembanding dalam melakukan penelitian. 


\section{Pengujian Data}

Pengujian hasil analisis dan dilakukan secara informasi (dalam bentuk naratif) dan formal (dalam bentuk tabel, grafik). Penyajian data dalam bentuk naratif untuk mengidentifikasi potensi yang ada sehingga diperoleh suatu gambaran lengkap dari permasalahan yang dibahas. Penyajian formal dilakukan untuk mendeskripsikan strategi pengembangan produksi di PT. Power Express Indonesia.

\section{Teknis Analisis Data}

Tujuan untuk menyederhanakan seluruh data yang terkumpul, menyajikan secara sistematik, kemudian mengolah, menafsirkan dan memaknai data tersebut. Analisis data merupakan upaya pemecahan permasalahan penelitian untuk memperoleh jawaban atas permasalahan yang diteliti. Permasalahan dalam penelitian ini akan dianalisis secara deskriptif kualitatif.

\section{HASIL ANALISIS DAN PEMBAHASAN}

\section{Data Hasil Kuesioner}

Data hasil kuesioner ini merupakan hasil dari pengolahan kuesioner yang telah di isi oleh reponden, yang telah dilakukan di PT. Power Express Indonesia.

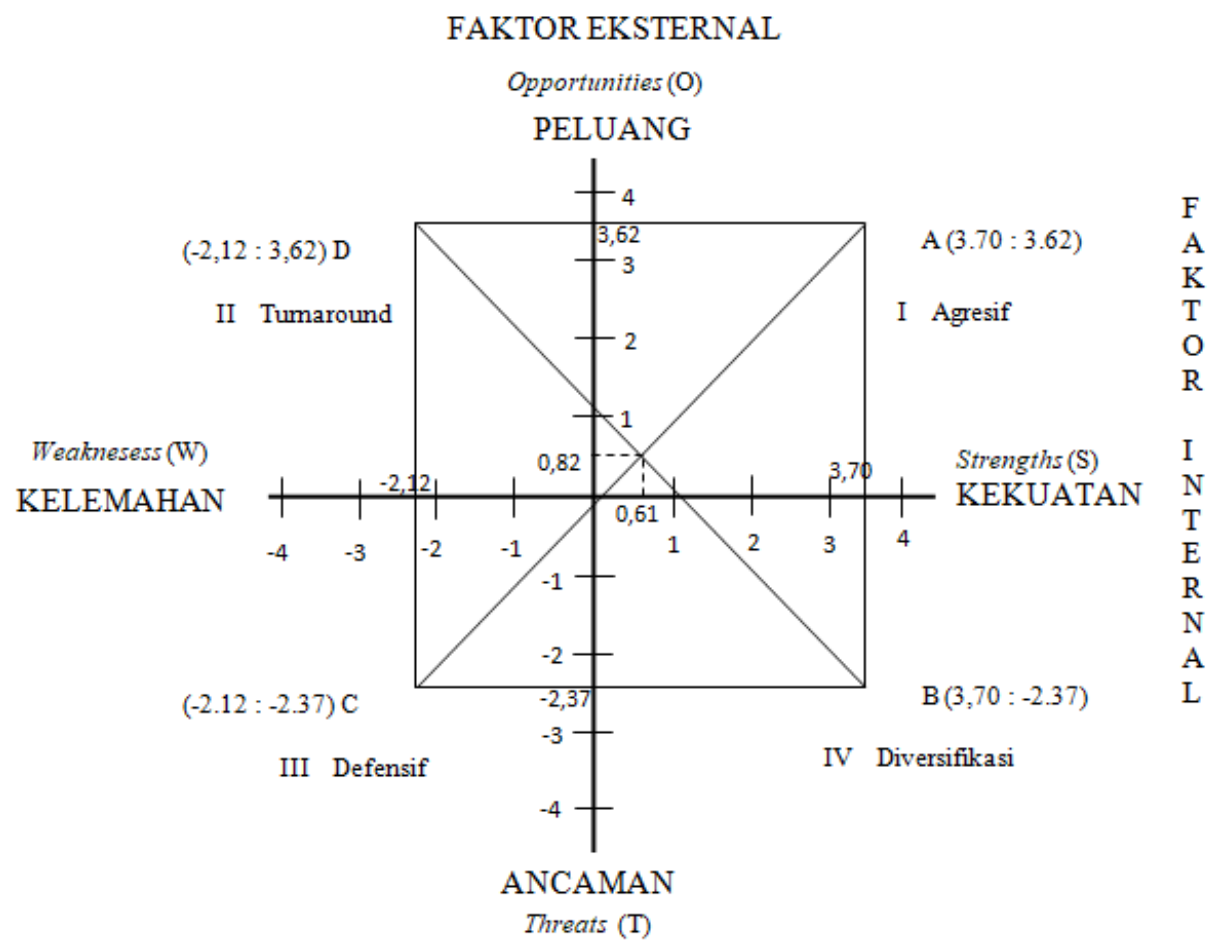

Sumber: Data Diolah, 2020

Gambar 2

Posisi PT. Power Express Indonesia 


\section{Luasan Matrik}

Dari hasil pengelolahan tersebut data untuk mengetahui luas matrik dan prioritas strategi pada tabel 5, maka dengan diperoleh hasil luas matrik tersebut pada kuadran I dengan luas matrik 13,39 tapi perlu diperhatikan juga bahwa luas matrik pada kuadran IV memiliki luas matrik yang cukup diperhitungkan yaitu 8,77.

\section{Data Evaluasi Faktor Internal}

Data ini merupakan hasil dari pengelolahan kuesioner faktor internal (Strength dan Weakneses), maka dapat ditampilkan dalam tabel 2.

\section{Data Evaluasi Faktor Eksternal}

Data ini merupakan hasil dari pengolahan kuesioner faktor eksternal (Opportunities dan Threath), maka dapat ditampilkan dalam tabel 3.

\section{Strategi untuk Manajemen yang Akan Datang}

PT. Power Express Indonesia di dalam usahanya untuk masa yang akan datang antara lain:

a. Strategi Strenght (S)

- Perusahaan diharapkan memperbaiki hubungan antara atasan dan bawahan untuk kenyamanan karyawan saat bekerja.

- Perusahaan diharapkan menambah armada perusahaan agar mempermudah pengiriman dan mengontrol barang sampai ke tujuan.

- Perusahaan diharapkan mempertahankan pemberian Reward dan Punishment agar karyawan mampu bekerja secara maksimal untuk mencapai target perusahaan.

- Perusahaan diharapan mempertahankan kecepatan pengiriman dengan harga yang terjangkau untuk meningkatkan pelanggan.

\section{Tabel 1}

Luasan Matrik dan Prioritas Strategi

\begin{tabular}{llccc}
\hline Kuadran & Posisi Titik & Luasan Matrik & Rangking & Prioritas Strategi \\
\hline I & Titik A $:(3,70: 3,62)$ & 13,39 & 1 & Agresif \\
II & Titik D : $(-2,12: 3,62)$ & 7,67 & 3 & Trun Around \\
III & Titik C $:(-2,12:-2,37)$ & 5,02 & 4 & Defensif \\
IV & Titik B $:(3,70:-2,37)$ & 8,77 & 2 & Diversifikasi \\
\hline
\end{tabular}

Sumber: Data Diolah, 2020

Tabel 2

Faktor Internal

\begin{tabular}{lll}
\hline No. & Faktor Strategis & Skor \\
\hline 1 & Faktor Kekuatan (Strenght) & 3,70 \\
2 & Faktor Kelemahan (Weakneses) & $-2,12$ \\
& Total & 1,58 \\
\hline
\end{tabular}

Sumber: Data Diolah, 2020 
Tabel 3

Faktor Eksternal

\begin{tabular}{lll}
\hline No. & Faktor Strategis & Skor \\
\hline 1 & Faktor Peluang (Opportunities) & 3,62 \\
2 & Faktor Ancaman (Threats) & $-2,37$ \\
& Total & 1,25 \\
\hline
\end{tabular}

Sumber: Data Diolah, 2020

b. Strategi Weaknessess (W)

- Perusahaan diharapkan meningkatkan kedisplinan karyawan agar tepat waktu, guna mencapai tujuan perusahaan

- Perusahaan diharapkan memperbaiki fasilitas tempat yang masih kurang luas menjadi fasilitas yang mewadai untuk kenyamanan kinerja karyawan.

- Perusahaan diharapkan meningkatkan pendidikan karyawan agar mendapatkan karyawan yang berkualitas.

- Perusahaan diharapan memperbaiki adanya beberapa komplain dari konsumen yang belum dilayani agar secepatnya di proses untuk kenyamanan konsumen.

c. Stategi Opportunities (O)

- Perusahaan diharuskan lebih bisa mengambil peluang dengan adanya pertambahnya penduduk di Indonesia yang semakin meningkat agar pertumbuhan pengiriman dapat meningkat juga.

- Memberikan harapan agar pemerintah bisa mendukung stabilitas perekonomian yang mulai tumbuh dan stabil demi mendukung jalannya perusahaan pengiriman barang.

- Perusahaan diharapkan meningkatkan pelayanan yang berkualitas agar pelanggan tetap banyak.

- Perusahaan diharapkan mempertahankan hubungan baik dengan pelanggan untuk meningkatkan aset perusahaan.

d. Strategi Threat $(\mathrm{T})$

- Perusahaan diharapkan dapat mengontrol penggunaan listrik, BBM, air guna menekan tingginya biaya operasional perusahaan.

- Perusahaan diharapkan meningkatkan keahlian tenaga kerja untuk menghadapi pesaing baru di bidang yang sama.

- Perusahaan diharapkan meningkatkan prosedur pengiriman barang secara ketat untuk mengantisipasi adanya ketidak jujuran pelanggan dalam menjelaskan isi paket.

- Perusahaan diharapkan memaksimalkan tingkat perkembangan teknologi untuk kelangsungan perusahaan secara jangka panjang.

\section{SIMPULAN DAN SARAN}

Hasil perhitungan dengan luasan tiap kuadran: Luasan pada Kuadran I: Mempunyai ragking pertama dalam perhitungan luasan kuadran ini adalah kuadran I sehingga perusahaan sebenarnya dalam posisi yang sangat menguntungkan karena perusahaan memiliki kekuatan yang cukup untuk memanfaatkan peluang yang tersedia. Saran - saran 
yang mungkin dapat diberikan kepada PT. Power Express Indonesia antara lain : PT. Power Express Indonesia harus memanfaatkan semua strategi SO dimana perusahaan memiliki kekuatan untuk memanfaatkan peluang yang ada, antara lain: Adanya pelatihan bagi karyawan untuk meningkatkan tenaga kerja yang berkualitas memenuhi standart untuk menjaga hubungan baik dengan pelanggan. Mempertahankan kecepatan pengiriman dengan harga yang terjangkau untuk peluang pasar yang besar dalam pertumbuhan sektor e-commerce. Keramahan Customer Service dalam bekerja sesuai dengan standart pelayanan yang membuat pelanggan tetap banyak.

\section{DAFTAR PUSTAKA}

AnggrianiRatih. 2019. Strategi Pengembangan Usaha Jamur Tiram Putib Melalui Analisis SWOT Ditinjau dari Ekonomi Islam. jurnal, InstitutAgama Islam Negri Bengkulu.

DaulayRoudhoh. H. 2018, Analisis SWOT Terhadap Perkembangan Usah a Kipang Desa Hutabaringi Kecamatan Siabu Kabupaten Mandailing Natal. jurnal. Universitas Islam Negeri Sumatera Utara Medan.

Komala Risma Dwi. 2019. Analisis Strategi Pemasaran Menggunakan AnalisisSWOT Studi pada Eduplex Coworking Space Bandung. jurnal, Universitas Telkom, 920.

LubisYuli Sahara. 2019. Analisis Potensi dan Strategi Pengembangan ProdukUnggulan di Kabupaten Padang Lawas. jurnal,Universitas Islam Negeri Sumatera Utara.

RangkutiFreddy. 2018. Analisis SWOT: Teknik Membedah Kasus Bisnis Cara Perbitungan Bobot, Rating, dan OCAI.Penerbit : PT Gramedia Pustaka Utama, Jakarta.

Rukajat Ajat. 2018. Pendekatan Penelitian Kualitatif (Qualitative Research Approach). Penerbit : Deepublish. Yogyakarta

Sedarmayanti. 2017. Perencanaan dan Pengembangan SDM untuk Meningkatkan Kompetensi, Kinerja, dan Produktifitas Kerja.Penerbit:PT Refika Aditama, Bandung.

Suladi Ica Try Dewi. 2019. Analisis SWOT sebagai strategi Pengembangan Usaba pada Aspek Operasional Perusahaan bidang jasa pada PT. Bina Informasi Optima Solusindo Surabaya. jurnal, Universitas Bhayangkara Surabaya.

Sodikin Dickdick. 2017. Manajemen Sumber Daya Manusia: Membangun Paradigma Baru. Penerbit: Salemba Empat, Jakarta. 
Lampiran 1. Kuesioner Internal Faktor Analisis Strategi Untuk Mengetahui Kekuatan (Strenght)

\begin{tabular}{|c|c|c|c|}
\hline Faktor Strategi & $\begin{array}{c}\text { Bobot } \\
(\mathrm{B})\end{array}$ & $\begin{array}{c}\text { Rating } \\
(\mathrm{R})\end{array}$ & $\begin{array}{c}\text { SKOR } \\
(\mathrm{S}=\mathrm{BXR}) \\
\end{array}$ \\
\hline \multicolumn{4}{|l|}{ MSDM } \\
\hline $\begin{array}{l}\text { 1. Proses rekuitmen dan seleksi tenaga kerja yang } \\
\text { berpontensi }\end{array}$ & 0,043 & 3,5 & 0,15 \\
\hline 2. Adanya pelatihan bagi karyawan & 0,052 & 3,4 & 0,18 \\
\hline 3. Adanya tunjangan kesehatan bagi karyawan & 0,049 & 3,9 & 0,19 \\
\hline 4. Pemberian Reward dan Punishment & 0,041 & 3,9 & 0,16 \\
\hline 5. Loyalitas kerja kepada perusahaan atau organisasi & 0,045 & 3,5 & 0,16 \\
\hline $\begin{array}{l}\text { 6. Tenaga kerja yang menguasai dan ahli di } \\
\text { bidangnya }\end{array}$ & 0,038 & 3,6 & 0,14 \\
\hline 7. Hubungan antara atasan dan bawahan baik & 0,046 & 3,8 & 0,18 \\
\hline 8. Kepemimpinan yang terbuka & 0,051 & 3,8 & 0,19 \\
\hline \multicolumn{4}{|l|}{ Operasional } \\
\hline 9. Bekerja sama dengan beberapa airline & 0,046 & 3,9 & 0,18 \\
\hline 10. Memiliki dukungan armada sendiri & 0,043 & 3,6 & 0,15 \\
\hline $\begin{array}{l}\text { 11. Melayani service pengiriman port to port / } \\
\text { bandara ke bandara ke seluruh wilayah indonesia }\end{array}$ & 0,053 & 3,5 & 0,18 \\
\hline 12. Memiliki standar kualitas operasional & 0,049 & 3,5 & 0,17 \\
\hline $\begin{array}{l}\text { 13. Memberikan jaminan (Assurance) untuk setiap } \\
\text { kiriman barang tertentu. }\end{array}$ & 0,040 & 3,4 & 0,13 \\
\hline 14. Jam operasional 24 jam nonstop 7 hari seminggu & 0,040 & 3,7 & 0,15 \\
\hline 15. Sudah bersertifikasi ISO & 0,046 & 3,6 & 0,17 \\
\hline \multicolumn{4}{|l|}{ Pelayanan } \\
\hline $\begin{array}{l}\text { 16. Keramahan Customer service dalam bekerja } \\
\text { sesuai dengan standart pelayanan }\end{array}$ & 0,052 & 4 & 0,21 \\
\hline 17. Customer service yang siap membantu 24 jam & 0,052 & 4 & 0,21 \\
\hline $\begin{array}{l}\text { 18. Melayani pengambilan barang dari kiriman } \\
\text { pesawat udara }\end{array}$ & 0,047 & 3,6 & 0,17 \\
\hline 19. Kecepatan pengiriman dan Harga yang terjangkau & 0,051 & 3,9 & 0,20 \\
\hline 20. Pilih sendiri jam keberangkatan barang & 0,037 & 3,5 & 0,13 \\
\hline 21. Layanan pengiriman PT. Power Express & 0,041 & 4 & 0,16 \\
\hline $\begin{array}{l}\text { Indonesia juga didukung dengan Tracking System } \\
\text { dan juga laporan status kiriman yang dipantau } \\
\text { melalui website. } \\
\text { 22. Melayani service incoming \& outgoing dengan } \\
\text { lead time yang dapat diandalkan }\end{array}$ & 0,040 & 3,6 & 0,14 \\
\hline TOTAL & 1,00 & & 3,70 \\
\hline
\end{tabular}

Sumber: Data Diolah, 2020 
Lampiran 2. Kuesioner Internal Faktor Analisis Strategi Untuk Mengetahui Kelemahan

\begin{tabular}{|c|c|c|c|}
\hline Faktor Strategis & $\begin{array}{l}\text { Bobot } \\
\text { (B) }\end{array}$ & $\begin{array}{l}\text { Rating } \\
\text { (R) }\end{array}$ & $\begin{array}{c}\text { Skor } \\
(\mathrm{S}=\mathrm{BXR})\end{array}$ \\
\hline \multicolumn{4}{|l|}{ MSDM } \\
\hline 1. Kedisplinan Karyawan & 0,116 & $-2,3$ & $-0,27$ \\
\hline 2. Komunikasi pemimpin terhadap bahwan & 0,101 & $-2,3$ & $-0,23$ \\
\hline 3. Pendidikan karyawan & 0,086 & -2 & $-0,17$ \\
\hline \multicolumn{4}{|l|}{ Operasional } \\
\hline 4. Fasilitas tempat masih kurang & 0,063 & -2 & $-0,13$ \\
\hline $\begin{array}{l}\text { 5. Dalam pendistribusian kiriman, masih terdapat kendala } \\
\text { apabila jadwal keberangkatan pesawat pengangkutan } \\
\text { terlambat. }\end{array}$ & 0,088 & $-3,3$ & $-0,29$ \\
\hline 6. Pengiriman hanya lewat udara & 0,101 & $-2,1$ & $-0,21$ \\
\hline 7. Minimal pengiriman $10 \mathrm{~kg}$ & 0,103 & -2 & $-0,21$ \\
\hline \multicolumn{4}{|l|}{ Pelayanan } \\
\hline 8. Banyak Komplain yang belum dilayani & 0,078 & $\begin{array}{l}-1 \\
-2,2\end{array}$ & $\begin{array}{l}-0,08 \\
-0,17\end{array}$ \\
\hline 9. Kekeliruan dalam mengirim barang & 0,050 & -2 & $-0,10$ \\
\hline 10. Keterlambatan pengiriman & 0,081 & -2 & $-0,16$ \\
\hline 11. Penambahan harga & 0,050 & -2 & $-0,10$ \\
\hline 12. Tidak bisa mengirim barang ke tempat tujuan customer & & & \\
\hline TOTAL & 1,00 & & $-2,12$ \\
\hline
\end{tabular}

Sumber: Data Diolah, 2020

Lampiran 3. Kuesioner Internal Faktor Analisis Strategi Untuk Mengetahui Peluang (Opportunities)

\begin{tabular}{lccc}
\hline \multicolumn{1}{c}{ Faktor Strategi } & $\begin{array}{c}\text { Bobot } \\
(\mathrm{B})\end{array}$ & $\begin{array}{c}\text { Rating } \\
(\mathrm{R})\end{array}$ & $\begin{array}{c}\text { SKOR } \\
(\mathrm{S}=\mathrm{BXR})\end{array}$ \\
\hline$\underline{\text { LINGKUNGAN MAKRO }}$ & 0,103 & 3,7 & 0,38 \\
1. Perekonomian yang mulai tumbuh dan stabil & 0,103 & 3,6 & 0,37 \\
2. Pertumbuhan penduduk indonesia yang kian meningkat & & & \\
3. Saranan Komunikasi yang semakin canggih & 0,089 & 3,7 & 0,28 \\
4. Tingkat Pendidikan yang semakin Canggih & 0,087 & 3,9 & 0,34 \\
5. Sistem politik di Indonesia mulai terarah & 0,096 & 2,7 & 0,26 \\
LINGKUNGAN MIKRO & & & \\
6. Pelanggan tetap banyak & 0,105 & 3,9 & 0,41 \\
7. Adanya hubungan baik dengan pelanggan & 0,103 & 3,9 & 0,40 \\
8. Petunjuk lokasi yang mudah dicari Konsumen & 0,109 & 3,8 & 0,40 \\
9. Peluang pasar yang besar & 0,105 & 3,9 & 0,41 \\
10. Pertumbuhan pesat sektor e-commerce & 0,103 & 3,6 & 0,37 \\
TOTAL & 1,00 & & 3,62 \\
\hline
\end{tabular}

Sumber: Data Diolah, 2020 
Lampiran 4. Kuesioner Internal Faktor Analisis Strategi Untuk Mengetahui Ancaman (Threat)

\begin{tabular}{lccc}
\hline \multicolumn{1}{c}{ Faktor Strategi } & $\begin{array}{c}\text { Bobot } \\
(\mathrm{B})\end{array}$ & $\begin{array}{c}\text { Rating } \\
(\mathrm{R})\end{array}$ & $\begin{array}{c}\text { SKOR } \\
(\mathrm{S}=\mathrm{BXR})\end{array}$ \\
\hline $\begin{array}{l}\text { LINGKUNGAN MAKRO } \\
\text { 1. Lemahnya nilai tukar rupiah terhadap mata uang asing }\end{array}$ & 0,103 & $-2,3$ & $-0,24$ \\
2. Tingginya biaya operasional (Listrik, BBM, dil) & 0,098 & $-2,1$ & $-0,20$ \\
3. Jasa luar negeri yang mulai masuk dalam negri & 0,054 & -2 & $-0,11$ \\
LINGKUNGAN MIKRO & & & \\
4. Banyak muncul pesaing baru & 0,098 & -2 & $-0,20$ \\
5. Kebijakan pemerintah yang tidak membatasi pendatang & 0,095 & -2 & $-0,19$ \\
$\quad$ baru & 0,108 & $-2,6$ & $-0,28$ \\
6. Adanya kerusakan pada barang konsumen & 0,122 & $-3,7$ & $-0,45$ \\
7. Adanya ketidak jujuran pelanggan dalam menjelaskan isi & & & $-0,17$ \\
$\quad$ paket (Narkoba, barang mudah kebakar) & 0,117 & $-1,5$ & $-0,15$ \\
8. Perkembangan Teknologi yang cepat dan dinamis & 0,084 & $-1,8$ & $-0,38$ \\
9. Transportasi udara yang sangat rentan dengan perubahan \\
$\quad$ cuaca & & & $-2,37$ \\
10. Pencurian & 0,122 & $-3,1$ & 1,00 \\
TOTAL
\end{tabular}

Sumber: Data Diolah, 2020

Lampiran 5. Diagram Matrik SWOT Strategi Perbaikan Utama

\begin{tabular}{|c|c|}
\hline $\begin{array}{l}\text { KEKUATAN (STRENGHT) } \\
\text { a. Pemberian Reward dan Punishment. } \\
\text { b. Hubungan antara atasan dan } \\
\text { bawahan baik. } \\
\text { c. Memiliki dukungan armada sendiri } \\
\text { d. Keramahan Customer service dalam } \\
\text { bekerja sesuai dengan standart } \\
\text { pelayanan } \\
\text { e. Kecepatan pengiriman dan Harga } \\
\text { yang terjangkau. }\end{array}$ & $\begin{array}{l}\text { KELEMAHAN (WEAKNESSES) } \\
\text { a. Kedisplinan Karyawan } \\
\text { b. Pendidikan karyawan } \\
\text { c. Fasilitas tempat masih kurang } \\
\text { d. Komunikasi pemimpin terhadap bahwan } \\
\text { e. Banyak Komplain yang belum dilayani }\end{array}$ \\
\hline $\begin{array}{l}\text { PELUANG (OPPORTUNITIES) } \\
\text { a. Perekonomian yang mulai tumbuh } \\
\text { dan stabil } \\
\text { b. Pertumbuhan penduduk indonesia } \\
\text { yang kian meningkat } \\
\text { c. Pelanggan tetap banyak } \\
\text { d. Adanya hubungan baik dengan } \\
\text { pelanggan } \\
\text { e. Peluang pasar yang besar }\end{array}$ & $\begin{array}{l}\text { ANCAMAN (THREAT) } \\
\text { a. Tingginya biaya operasional (Listrik, } \\
\text { BBM,dll) } \\
\text { b. Jasa luar negeri yang mulai masuk } \\
\text { dalam negri } \\
\text { c. Banyak muncul pesaing baru } \\
\text { d. Kebijakan pemerintah yang tidak } \\
\text { membatasi pendatang baru } \\
\text { e. Adanya ketidakjujuran pelanggan dalam } \\
\text { menjelaskan isi paket (Narkoba, barang } \\
\text { mudah kebakar) } \\
\text { f. Perkembangan Teknologi yang cepat } \\
\text { dan dinamis. }\end{array}$ \\
\hline
\end{tabular}

Sumber: Data Diolah, 2020 